\title{
DISCUSSION
}

\section{Sand state from cone penetrometer tests: a framework considering grain crushing stress}

\author{
J.-M. KONRAD (1998). Géotechnique 48, No. 2, 201-215
}

\section{J. A. Schneider, P. W. Mayne and A. V. McGillivray, Georgia Institute of Technology}

The work of previous researchers demonstrates the need for tip resistance correction, because of size effects in calibration chambers. The author did not apply these corrections, and therefore there is some question with the analyses presented.

Houlsby \& Yu (1990) and Schnaid \& Houlsby (1991) present the results of chamber-size effects determined from an experimental database as well as a finite element model. They conclude that chamber size can affect results at all densities, but more significantly in dense soils. From the work of Parkin \& Lunne (1982), a field reference chamber/cone diameter ratio of 50 was used. In a chamber with a ratio of about 33 cone diameters, their model predicts an error or $30-50 \%$ for a range of densities.

Mayne \& Kulhawy (1991) evaluated chamber-size effects from an experimental database of over 640 separate tests. Their study concluded that a field reference chamber/cone diameter ratio of 70 should be used. In a chamber with a ratio of 33 cone diameters, an error of $17-45 \%$ would occur for the range of densities used for calibration chamber tests on Ticino sand. Since Ticino sand comprised a large portion of the Mayne \& Kulhawy database, there is confidence that this correction is needed.

Salgado et al. (1997) compared a cavity expansion model with calibration chamber data to evaluate cone tip resistance. Tip resistance is a function of relative density, vertical and horizontal effective stress, chamber to cone diameter ratio, and chamber boundary condition. Differences between flexible and rigid chambers under the same boundary condition were also mentioned. A flexible chamber can only maintain an average of zero lateral displacement, while a rigid chamber will have zero lateral displacement along the sample height.

The study at Laval was performed in a rigid-wall container, apparently under BC2 (defined in Lunne et al., 1997), while the studies by Baldi et al. (1982, 1986) were performed in a flexible-wall container, predominantly under $\mathrm{BC} 1$ and $\mathrm{BC} 3$. It can be expected that the cone resistance would need to be increased for a flexible boundary, and cone resistance would need to be reduced to account for rigid boundary conditions (Yu \& Mitchell, 1998).

In conclusion, the authors of this discussion feel that three important points require additional clarification by the author:

(a) Despite similar chamber/cone diameter ratios, the ISMES calibration chamber and the University of Laval calibration chamber are not similar, and the data from these two studies are not directly comparable.

(b) In calibration chambers with chamber/cone diameter ratios of about 30, correction factors are not close to unity, especially at the relative densities used in this study (about $55-85 \%$ ). When comparing flexible- and rigid-wall chambers, these errors will compound. Correction factors are available for flexible-wall chambers, but more research is needed for size effects in rigid-wall containers.

(c) What boundary conditions were used during these experiments, and how did they compare with those used for other data presented in this paper? How was reduction in applied stress by side shear along the rigid walls accounted for in the experiments?
Even though the data evaluated under the proposed new framework agree relatively well, Ticino data from the present study should have greater tip resistance than data from the Baldi et al. (1982, 1986) studies because of chamber size effects. Adequate CPT data can be obtained using relatively small calibration chambers provided proper correction factors are applied.

\section{Author's reply}

The discussers have raised a single point with respect to calibration chamber size effects and the need for tip resistance correction. The main purpose of the paper was to propose a framework for interpreting the results of cone penetrometer tests (CPTs) in sands that considers the bi-linear nature of the critical-state line in an $e-\log p^{\prime}$ space. One of the key features of the framework was the use of Ticino sand as a reference sand because of the quantity and quality of data available in the literature using the ISMES calibration chamber. The proposed CPT interpretation method for a different sand does not require any test in any calibration chamber of any size. This was well demonstrated by Konrad (1997) for two sites: a fine tailings sand and a natural sand deposit in the Fraser River delta. Close agreement between void ratios inferred from the proposed CPT interpretation method and those measured from in-situ frozen samples was obtained at the tailings site, which is a relatively young deposit. However, the analysis of CPT data at the Fraser River delta suggested that ageing affected the penetration resistance, and hence the in-situ state. Since the calibration chamber data are generally obtained for freshly deposited sands, it follows that CPT values in the field also need to be corrected for ageing.

Now back to the discussion about size effects. The small calibration chamber developed at Laval University was used to illustrate the effect of different sand types on CPT results. One of the objectives pursued was to minimise time and costs, which was realised although at the expense perhaps of quality of data. But again, the framework was based solely on Ticino sand results from ISMES and not from U. Laval. A close examination of Fig. 11 of the paper shows clearly that the CPT data from the smaller calibration chamber lie above the reference data obtained by ISMES. This reflects both the size effect and a different wall boundary condition (rigid versus flexible). As stated by the discussers, the U. Laval data should indeed have a greater tip resistance than data from Baldi et al. (1982).

\section{REFERENCES}

Baldi, G., Belloti, R., Ghionna, V., Jamiolkowski, M. \& Pasqualini, E. (1982). Design parameters for sands from CPT. Proc. 2nd Eur. Symp. Penetration Testing, ESOPT II, Amsterdam, 425-432.

Baldi, G., Belloti, R., Ghionna, V., Jamiolkowski, M. \& Pasqualini, E. (1986). Interpretation of CPTs and CPTUs. Part 2: Drained penetration of sands. Proc. 4th Int. Geotech. Sem. Field Instrumentation and In Situ Measurements, Singapore, 143-156.

Houlsby, G. T. \& Yu, H. S. (1990). FInite element analysis of the conepressuremeter test. In Pressuremeters, London: Thomas Telford, pp. 221-300.

Konrad, J.-M (1997). In situ sand state from CPT: evaluation of a unified approach at two Canlex sites. Can. Geotech. J. 34, 120-130.

Lunne, T., Robertson, P. K. \& Powell, J. J. M. (1997). Appendix C: Calibration chamber testing of sandy soils. In Cone penetration 
testing in geotechnical practice, New York: Blackie Academic \& Professional. pp. 291-304.

Mayne, P. W. \& Kulhawy, F. H. (1991). Calibration chamber database and boundary effects correction for CPT data. In Calibration chamber Testing. New York: Elsevier, pp. 257-264.

Parkin, A. K. \& Lunne, T. (1982). Boundary effects in laboratory calibration of a cone penetrometer in sand. Proc. 2nd Eur. Symp. Penetration Testing. ESOPT II, Amsterdam 2, 761-768.
Salgado, R., Mitchell, J. K. \& Jamiolkowski, M. (1997). Cavity expansion and penetration resistance in sand. J. Geotech. Geoeniviron. Engng 123, No. 4, 344-354.

Schnaid, F. \& Houlsby, G. T. (1991). An assessment of chamber size effects in the calibration of in situ tests. Géotechnique 41, No. 3, 437-446.

Yu, H. S. \& Mitchell, J. K. (1998). Analysis of cone resistance: review of methods. J. Geotech. Geoenviron. Engng 124, No. 2, 140-149. 